DOI:10.36108/jvbs/8102.10.0120

\title{
Preliminary Evaluation of Methanol Extract of Aframomum melegueta seed for Hypoglycaemic Effect in Rats
}

\author{
Olaitan H. M., *Nwinyi F. C, Akumka D. D, and Mohammed A. \\ Department of Veterinary Pharmacology and Toxicology, \\ University of Abuja, Abuja
}

\begin{abstract}
Diabetes is a metabolic disease that has caused severe health complications and premature deaths in both developed and developing countries. It is characterized by hyperglycaemia. This study was designed to investigate the hypoglycaemic effect of methanol extract of Aframomum melegueta seed in Alloxan-induced diabetic rats. Adult albino rats of either sex weighing between $90-150 \mathrm{~g}$ were used. Diabetes was induced by administration of alloxan $(100 \mathrm{mg} / \mathrm{kg}$ i.p). The rats were seperated into 5 groups of five rats each. Group I served as the negative control and was given normal saline (10 ml/kg p.o). Groups II - IV were given A. melegueta extract at varying doses of 100, 200 and $400 \mathrm{mg} / \mathrm{kg}$ p.o respectively. Group V was treated with Glibenclamide at a dose of 2 $\mathrm{mg} / \mathrm{kg}$ p.o to serve as the positive control. The various treatments were administered for a period of 14 days. The Fasting Blood Glucose (FBG) levels of the rats were determined before and weekly after commencement of treatment with the aid of a glucometer using blood collected from the tail vein. Result revealed that there was a significant $(p<0.05)$ reduction of the Fasting Blood Glucose level after 14 days of treatment in the diabetic groups as compared to the FBG before the treatment. However, there was no significant difference $(p>0.05)$ in the mean Fasting Blood Glucose levels between groups treated with varying doses of A. melegueta seed extract. Also, there was no significant difference $(p>0.05)$ between groups treated with A. melegueta extract and the group treated with Glibenclamide. The investigation showed that A. melegueta seed extract had hypoglycaemic effect in Alloxan - induced diabetic rats which was comparable with that of Glibenclamide, a conventionally used hypoglycaemic drug. However, the hypoglycaemic effect of the extract was not dose dependent. This therefore suggests that Aframomum melegueta seed has a useful potential for the treatment of diabetes mellitus due to its hypoglycaemic effect.
\end{abstract}

Keywords: Aframomum melegueta, Diabetes mellitus, Fasting Blood Glucose, Hypoglycaemia, Glibenclamide.

*Corresponding email: fchyme@yahoo.co.uk

Tel: $+234(0) 8023215755$

This Paper was accepted on 15th November, 2017 and published 24th April, 2018 


\section{Hypoglycaemic Effect of Aframomum melegueta seed}

\section{INTRODUCTION}

Diabetes is a metabolic disorder characterized by hyperglycaemia caused by the destruction of the $\beta$-cells of the pancreas or cellular resistance to the action of insulin. It is usually associated with absolute or relative deficiencies in insulin secretion or insulin action [1]. Diabetes is a life threatening, common and very prevalent disease affecting citizens of both developed and developing countries. In other words, it is a global health problem and there is serious need to combat the disease.

The World Health Organization (WHO) estimated the disease in adults to be around 173 million in year 2000, two-third of which lived in developing countries [2]. The prevalence of diabetes mellitus would be on the increase by $5.4 \%$ in 2025 [3]. Diabetes is categorized into two main types; Type 1 diabetes or juvenile diabetes and type 2 diabetes or adult - onset diabetes. Classical symptoms of diabetes include polyuria, polydipsia, polyphagia and weight loss. It is a major cause of severe health complications and premature deaths in many developing countries [4]. Several conventional drugs are useful in the treatment of diabetes mellitus and they treat diabetes by lowering glucose levels in the blood. However, some of these medications produce diverse functional and morphological alterations, some of which lead to severe complications of the eye, kidney and heart [5]. Most of these synthetic agents are also relatively expensive for developing countries [6] Therefore, there is the need to search for more agents that can either compliment or serve as better alternatives to the existing anti-diabetics The use of herbal medicine is gaining popularity both in developing and developed countries because of their natural origin and less side effects [7]. The importance of anti-diabetic plants in the development of economic and effective treatment for diabetes has been recognized by the World Health Organization [8]. The use of herbal remedies for the treatment of diabetes has also been authenticated by World Health Organization [9]. Aframomum melegueta is a herbaceous perennial plant species belonging to the family Zingiberaceae (Ginger family). It is native to the swampy habitats along West African Coast. Depending on the country, it is called several names including Melegueta pepper, Alligator pepper and Guinea pepper. In Nigeria, it is called Atare (Yoruba), Ose oji (Ibo) and Citta (Hausa). It is one of such plants having both medicinal and nutritive values and popularly used as herbal remedy against a wide range of ailments both in Nigeria and several other countries of the world [10]. Various parts of this plant have been claimed to possess medicinal properties. The seeds are used for treatment of diarrhoea, stomach ache, as a carminative and for inflammatory conditions $[11 ; 12 ; 13]$. It has been established to be a potent antifungal agent [14]; It is used for treatment of snake bites [15] and has antioxidant and antitumor effects [16]. Traditionally, a herbal mixture of Alligator pepper seed (Aframomum melegueta) and water leaf (Talinum triangulare) has been acclaimed to be effective in the treatment of diabetes in human in some areas of Oyo State, 


\section{Hypoglycaemic Effect of Aframomum melegueta seed}

Nigeria. However, no scientific study has been carried out to verify this claim. This research work is aimed at the evaluation of hypoglycaemic effect of methanol extract of Aframomum melegueta seed.

\section{MATERIALS AND METHODS}

\section{Plant collection and preparation of crude} extract

Aframomum melegueta fruits were obtained from Iddo Sarki, Abuja, Nigeria. The fruits were identified by a Plant Taxonomist in the Department of Botany, University of Abuja, Nigeria. The seeds were removed from the fruit and the dried seeds were pulverized with the aid of a mortar and pestle to obtain a uniform powder.

The pulverized sample (356 g) was soaked in $1000 \mathrm{ml}$ of absolute methanol and stirred at intervals for a period of $24 \mathrm{~h}$, after which the sample was filtered using a muslin cloth. The filtrate was collected in a beaker and concentrated to dryness using a water bath at $50{ }^{\circ} \mathrm{C}$. The dried extract was stored in a beaker at $4{ }^{\circ} \mathrm{C}$ until required.

\section{Drug and Chemicals}

Glibenclamide (Clezide ${ }^{\circledR}$, Jiangsu Pharmaceutical, China) Alloxan Monohydrate (Sigma-Aldrich) and Methanol (SigmaAldrich) were used for the research.

\section{Experimental animals}

Adult Wistar rats weighing between 90-150 g obtained from the National Veterinary Research Institute, VOM, Nigeria were used in the study. The rats were kept in well-ventilated cages under normal environmental conditions (12 h light and $12 \mathrm{~h}$ dark cycles) in the Faculty of Veterinary Medicine, University of Abuja, Nigeria for two weeks to acclimatize. The rats were fed with growers mash (Vital Feed Nig. $\left.\mathrm{Ltd}^{\circledR}\right)$ and given water ad libitum.

\section{Acute toxicity study}

The study was carried out by administering graded doses of the plant extract $(250 \mathrm{mg} / \mathrm{kg}$, $500 \mathrm{mg} / \mathrm{kg}, 1000 \mathrm{mg} / \mathrm{kg}$ and $2000 \mathrm{mg} / \mathrm{kg}$ ) orally to rats in four different groups. The animals were observed for changes in behaviour and/or mortalities for $72 \mathrm{~h}$. The study was aimed at calculating the median lethal dose $\left(\mathrm{LD}_{50}\right)$ of the plant extract.

\section{Measurement of Fasting Blood Glucose levels}

Fasting Blood Glucose levels of the rats were measured with TRUEresult ${ }^{\circledR}$ glucometer using blood sample obtained from the tail vein. The rats were weighed and fasted $12 \mathrm{~h}$ (overnight) prior to each blood glucose measurement. FBG measurement was done before treatments to obtain the baseline blood glucose levels in all the fasted rats. Weekly measurements were then taken following the commencement of treatments for a period of 2 weeks.

\section{Induction of diabetes mellitus}

Diabetes was induced by administration of freshly prepared solution of Alloxan monohydrate $(100 \mathrm{mg} / \mathrm{kg})$ intraperitoneally using insulin syringes. $72 \mathrm{~h}$ after administration of Alloxan, the Fasting Blood Glucose levels of the rats were measured again 


\section{Hypoglycaemic Effect of Aframomum melegueta seed}

and rats with Fasting Blood Glucose level > $9.5 \mathrm{mmol} / \mathrm{L}$ were classified as diabetic and were used for the study.

\section{Experimental design}

The rats were grouped into five (5) different groups of 5 rats each. The grouping is as follows:

Group I-Negative control (normal rats that received normal saline, $10 \mathrm{ml} / \mathrm{kg}$ )

Group II - Diabetic rats administered 100 $\mathrm{mg} / \mathrm{kg}$ of $A$. melegueta seed extract Group III - Diabetic rats administered 200 $\mathrm{mg} / \mathrm{kg}$ of $A$. melegueta seed extract Group IV - Diabetic rats administered 400 $\mathrm{mg} / \mathrm{kg}$ of $A$. melegueta seed extract Group V - Diabetic rats administered $2 \mathrm{mg} / \mathrm{kg}$ Glibenclamide to serve as the positive control.

The extract and Glibenclamide were administered via the oral routes with the aid of an oropharyngeal cannular for a period of 14 days.

The rats were weighed at the onset of the study and then weighed weekly throughout the duration of the experiment ( 2 weeks).

\section{Statistical analysis}

Data obtained were expressed as mean \pm standard error of mean (SEM) and analysed statistically by one way analysis of variance (ANOVA) using the SPSS version 16. P values $<0.05$ were considered statistically significant. Least Significant Difference (LSD) was applied to determine the differences between the groups.

\section{RESULTS}

\section{Plant extraction}

The methanol extract of Aframomum melegueta seed was a brownish, slightly oily semi-solid mass. The w/w percentage yield of the extract was $4.99 \%$

\section{Acute toxicity study}

No toxicity sign was observed and no mortality was recorded at all the tested doses $(250,500$, 1000 and $2000 \mathrm{mg} / \mathrm{kg}$ p.o) within $72 \mathrm{~h}$ of administration of the plant extract.

\section{Induction of diabetes mellitus}

The result showed that on day 3 (72 h) after administration of alloxan monohydrate (100 $\mathrm{mg} / \mathrm{kg}$ i.p) to the rats, there was a significant ( $\mathrm{p}$ $<0.05$ ) increase in Fasting Blood Glucose (FBG) level of alloxan-treated rats when compared with their baseline FBG values and those of the normal negative control rats.

\section{Measurement of Fasting Blood Glucose levels}

The result of the effect of methanol extract of Aframomum melegueta seed on Fasting Blood Glucose levels of alloxan-induced diabetic rats showed that on day 7 (i.e 7 days post treatment with A. melegueta seed extract), the Fasting Blood Glucose level in all the treatment groups (100, 200, $400 \mathrm{mg} / \mathrm{kg}$ A. melegueta extract and $2 \mathrm{mg} / \mathrm{kg}$ p.o Glibenclamide) were reduced. However, the reduction was significant ( $p$ $<0.05$ ) only at doses of 100 and $400 \mathrm{mg} / \mathrm{kg} \mathrm{p.o}$ of A. melegueta extract and $2 \mathrm{mg} / \mathrm{kg}$ p.o Glibenclamide when compared with the negative control group and their own FBG on day 1 . On day 14 post treatment with $A$. melegueta extract, the Fasting Blood Glucose level in the diabetic induced groups showed a significant decrease $(p<0.05)$ when compared with the Fasting Blood Glucose values on day 1. Also, there was no significant difference 
$(p>0.05)$ in Fasting Blood Glucose level between all the treatment groups compared to the negative control group. Groups administered the extract $(100,200$ and 400 $\mathrm{mg} / \mathrm{kg}$ p.o) also showed no significance difference $(p>0.05)$ in Fasting Blood Glucose level when compared with the group administered Glibenclamide ( $2 \mathrm{mg} / \mathrm{kg}$ p.o). There was no significant difference $(\mathrm{p}>0.05)$ in the Fasting Blood Glucose level within groups administered varying doses of the extract (100, 200 and $400 \mathrm{mg} / \mathrm{kg}$ p.o; Table I).

Table I: Effect of methanol extract of $A$. melegueta seed (100 - $400 \mathrm{mg} / \mathrm{kg} \mathrm{p.o)} \mathrm{on}$ Fasting Blood

Glucose levels of Alloxan-induced diabetic rats.

\begin{tabular}{clcccr} 
& & \multicolumn{3}{c}{ A. melegueta $(\mathrm{mg} / \mathrm{kg}, \mathrm{p} . \mathrm{o})$} & \multicolumn{2}{c}{$\begin{array}{c}\text { Glibenclamide } \\
\text { Day }\end{array}$} & Normal saline & 100 & 200 & 400 & 2mg/kg p.o \\
\cline { 3 - 5 } & $3.87 \pm 0.18$ & $4.20 \pm 0.17$ & $3.30 \pm 0.30$ & $3.47 \pm 0.18$ & $3.97 \pm 0.58$ \\
1 & $3.87 \pm 0.18$ & $11.17 \pm 1.24^{*}$ & $10.90 \pm 0.38^{*}$ & $9.70 \pm 1.54^{*}$ & $10.63 \pm 1.58^{*}$ \\
7 & $2.63 \pm 0.39$ & $5.80 \pm 1.71^{* *}$ & $10.43 \pm 1.58$ & $4.43 \pm 0.33^{* *}$ & $8.00 \pm 0.68^{* *}$ \\
14 & $3.40 \pm 0.30$ & $2.83 \pm 0.19^{* *}$ & $4.90 \pm 1.25^{* *}$ & $3.80 \pm 0.10^{* *}$ & $3.20 \pm 0.16^{* *}$ \\
\hline
\end{tabular}

* significant increase $(P<0.05)$ of FBG compared with their day zero (Day 0$)$ values and the values for the control group.

${ }^{* *}=$ significant $(P<0.05)$ reduction of FBG compared to their Day 1 values and the values for the control Group (One - way ANOVA and LSD)

Day $0=$ FBG values before treatment with alloxan monohydrate $(100 \mathrm{mg} / \mathrm{kg}$ i.p)

Day $1=$ FBG values $72 \mathrm{~h}$ post treatment with alloxan monohydrate $(100 \mathrm{mg} / \mathrm{kg}$ i.p $)$

\section{Effect of methanol extract of $A$. melegueta seed on body weight of alloxan-induced diabetic rats}

The result of the effect of methanol extract of Aframomum melegueta seed (100, 200 and $400 \mathrm{mg} / \mathrm{kg}$ p.o) on body weight of Alloxan induced diabetic rats showed that there was no significant difference $(p>0.05)$ in the body weight of the rats treated with the extract and those treated with Glibenclamide $(2 \mathrm{mg} / \mathrm{kg} \mathrm{p.o}$ ) when compared with the negative control group throughout the 14 days of the experiment (Table 2).

Table II : Effect of methanol extract of $A$. melegueta seed $(100-400 \mathrm{mg} / \mathrm{kg} \mathrm{p.o})$ on body weight of Alloxan-induced diabetic rats

\begin{tabular}{cccccc}
\hline & & \multicolumn{3}{c}{ A. melegueta $(\mathrm{mg} / \mathrm{kg}, \mathrm{p} . \mathrm{o})$} & \multicolumn{2}{c}{$\begin{array}{c}\text { Glibenclamide } \\
\text { Days }\end{array}$} & Normal saline & 100 & 200 & 400 & $2 \mathrm{mg} / \mathrm{kg} \mathrm{p.o}$ \\
\hline 0 & $109.27 \pm 4.65$ & $107.40 \pm 15.89$ & $102.80 \pm 6.58$ & $106.80 \pm 7.36$ & $103.40 \pm 8.50$ \\
7 & $130.00 \pm 2.02$ & $106.10 \pm 15.00$ & $103.67 \pm 5.23$ & $119.10 \pm 8.28$ & $135.80 \pm 3.92$ \\
14 & $127.67 \pm 7.27$ & $102.00 \pm 16.58107 .67 \pm 7.55$ & $124.67 \pm 7.34$ & $136.00 \pm 5.72$ \\
\hline
\end{tabular}




\section{Hypoglycaemic Effect of Aframomum melegueta seed}

\section{DISCUSSION}

The acute toxicity study showed that no toxicity sign or mortality was observed at all the tested doses of Aframomum. melegueta seed extract (250, 500, 1000 and $2000 \mathrm{mg} / \mathrm{kg}$ p.o) indicating that the oral median lethal dose $\left(\mathrm{LD}_{50}\right)$ of $A$. melegueta seed extract is $\geq 2000$ $\mathrm{mg} / \mathrm{kg}$. This suggests that the extract may be relatively safe. Estimated $\mathrm{LD}_{50}$ value $>1 \mathrm{~g}$ is considered safe [17].

The result also showed that the Fasting Blood Glucose levels of rats treated with alloxan monohydrate $(100 \mathrm{mg} / \mathrm{kg}$ i.p) increased $72 \mathrm{~h}$ post treatment when compared with the FBG of the same rats on Day 0 and those of the negative control group as seen in table 1 . This increase in Fasting Blood Glucose levels in the diabetes induced groups is indicative of the hyperglycaemic effect of alloxan following its ability to destroy the pancreatic islets cells. Thus, confirming the induction of diabetes mellitus [18] in those groups.

The study further revealed that on Day 7 post treatment with A. melegueta seed extract (100, 200 and $400 \mathrm{mg} / \mathrm{kg}$ p.o), the Fasting Blood Glucose level in all the diabetes induced groups got reduced as well as the FBG levels of rats treated with glibenclamide ( $2 \mathrm{mg} / \mathrm{kg}$ p.o). This suggests that the seed extract of $A$. melegueta has hypoglycaemic activity. Also on day 14 , the result showed that the extract further caused a reduction in Fasting Blood Glucose levels at all the tested doses (100, 200 and $400 \mathrm{mg} / \mathrm{kg} \mathrm{p.o)}$. This reduction was significant $(\mathrm{p}<0.05)$ when compared with their own FBG values on Day 1. This reduction on Day 14 was however, not significantly different $(p>0.05)$ from the FBG values for the negative control group. A significant $p<0.05$ reduction was also produced on Day 14 by Glibenclamide ( $2 \mathrm{mg} / \mathrm{kg}$ p.o) which was the reference standard drug when compared with its values on Day 1 but the reduction was also not significant $(\mathrm{p}>0.05)$ when compared with the FBG values of the negative control group. The non-significant reduction observed in all the treatment groups 14 days post treatment when compared with the negative control group probably suggests that the blood glucose level in all the diabetic - induced groups got normalized by the action of the A. melegueta seed extract and Glibenclamide as the case may be. This could also suggest that $A$. melegueta seed extract does not produce hypoglycaemic effect in normoglycaemic condition. Also a non-significant difference observed in the groups treated with the extract when compared with the group treated with the standard reference drug suggests that the hypoglycaemic effect of Aframomum melegueta extract is comparable with that of Glibenclamide.

It is worthy to note from the result that although Aframomum melegueta seed extract $(100,200$ and $400 \mathrm{mg} / \mathrm{kg}$ p.o) reduced the Fasting Blood Glucose levels of alloxan induced diabetic rats, the hypoglycaemic effect of the extract was not dose-dependent. Earlier report showed that the leaf extract of $A$. melegueta had hypoglycaemic effect on alloxan-induced diabetic rats and the effect 


\section{Hypoglycaemic Effect of Aframomum melegueta seed}

was observed to be dose-dependent [19]. This probably shows that the active principles producing the hypoglycaemic effect reside in both the leaf and seed of $A$. melegueta.

There was no significant difference $(\mathrm{p}>0.05)$ in the body weight of the rats treated with the extract and those treated with Glibenclamide when compared with the negative control group on Day 7 and Day 14. Earlier report showed that the aqueous leaf extract of $A$. melegueta caused a significant effect on body weight gain of diabetic rats only at a higher dose of $200 \mathrm{mg} / \mathrm{kg}$ and not at $100 \mathrm{mg} / \mathrm{kg}$ or lower doses [19]. Weight loss is one of the classical symptoms of diabetes [4]. The inability of the seed extract of $A$. melegueta to enhance the body weight suggests that it may not have influenced the metabolic processes and therefore cannot be taken advantage of in the improvement of body weight while being used as hypoglycaemic agent.

Based on the results of this preliminary work, methanol extract of the seed of Aframomum melegueta has significant $(\mathrm{p}<0.05)$ hypoglycaemic effect in alloxan-induced diabetic rats. The hypoglycaemic effect of the extract $(100-400 \mathrm{mg} / \mathrm{kg} \mathrm{p.o})$ is comparable to that of Glibenclamide $(2 \mathrm{mg} / \mathrm{kg}$ p.o). Thus Aframomum melegueta seed has a potential in the treatment of diabetes mellitus. However, further studies on the precise mechanism of action of Aframomum melegueta seed extract in reducing hyperglycaemia and isolation of the active ingredients responsible for the pharmacological activity would be necessary. Also, further toxicity studies including subacute and chronic studies would be carried out to ascertain the degree of safety on a long term use. A more prolonged study to show a clearer effect of Aframomum melegueta on body weight would also be worthwhile in subsequent research.

\section{REFERENCES}

1. Bhupesh C. S, Jjitendra G., Sonia S., Yogesh K. and Mahendra G. (2009). Antihyperglycaemic Activity of Root of Berberis aristata DC in Alloxaninduced Diabetic Rats. International Journal of Green Pharmacy, 3 (3): 259 -262 .

2. Wild S, Roglic G., Green A, Sicree R. and King H. (2004). Global Prevalence of Diabetes: Estimates for the Year 2000 and Projections for 2030. Diabetes Care, 27(5): 1045-1053.

3. Moller D. E and Flier J.S. (1991). Insulin resistance - mechanism, syndromes and implications. New England Journal of Medicine, 325: 938-948.

4. Cooke D.W. and Plotnick L. (2008). "Type 1 Diabetes Mellitus in Pediatrics". Pediatrics in Review, 29(11):374 84; Quiz 385. Doi: 10, 1542/pir 29-11-374. PMID 18977856.

5. Mac Gilliury, M.H., Voorhes, M.L., Putnam,T.I.(1982). Hormone and Metabolism Profiles in Children and Adolescents with Type 1Diabetes Mellitus. Diabetes Care, 5(suppl.): 3847.

6. Rubin, R.J., Altman, W.M., and Mendelson, D.N (1992). Health care 


\section{Hypoglycaemic Effect of Aframomum melegueta seed}

expenditures for people with diabetes mellitus, 1992. Journal of Clinical Endocrinology and Metabolism, 78: 809A-809F.

7. Modak M., Dixit P., Londhe J., Ghaskadbi J., Paul T. and Devasagayam A. (2007). Indian Herbs and Herbal Drugs used for the Treatment of Diabetes. Journal of Clinical Biochemistry and Nutrition, 40: 163-173.

8. World Health Organisation (1985). Diabetes mellitus: Report of a WHO study Group, Geneva, World Health Organisation Technical Report Series 727

9. Bailey C.J. and Day C. (1989). Traditional plants medicines as treatment for diabetes. Diabetes care, 12:553-564.

10. Agoha R.C. (1974). Medicinal Plant of Nigeria. Offsetdikker Facuitect Waskunden Natnurwenten Schoppen. Pp 22:158.

11. Kokwaro J.O (1976). Medicinal Plants of East Africa. Nairobi, Kenya, General Printers Ltd. pp. 244.

12. Houghton P.J and Osibogun I.M. (1993). Flowering plants used against snakebite. Journal of Ethno pharmacology, 39:235-236.

13. Rafatullah S, Galal A. M., Al-Yahya M.A. and Al-Said M.So. (1995). Gastric and Duodenal Anti-Ulcer and Cytoprotective Effects of Aframomum melegueta in Rats. International
Journal of Pharmacognosy, 33: 311 316.

14. Okigbo R.N and Ogbonnaya U.O. (2006). Antifungal Effects of two Tropical Plant Leaf Extracts (Ocimum gratissium and Aframomum melegueta) on Post-Harvest Yam (Dioscorea spp) Rot. African Journal of Biotechnology, 5:727-731.

15. Nebojsa L., Barbara M., Alexander P. and Ilya R. (2010). Toxicological Evaluation of Grains of Paradise (Aframomum melegueta). Journal of Ethnopharmacology,127 (2): 352 356.

16. Chan K.C., Choo N.R., Abdullahi A. and Ismail Z. (2004). Antiplasmodial Studies of Eurycoma Longifolia Jack using the Lactate Dehydrogenase Assay of Plasmodium falciparum. Journal of Ethnopharmacology, 92:223-227.

17. Lorke D (1983). A new approach to practical acute toxicity testing. Archives of Toxicology, 54:275-287.

18. Carvalho E.N., Carvalho N.A.S and Ferreira I.M. (2003). Experimental model of induction of diabetes mellitus in rats. Acta Cirurgica Brasileira, 18:60-64.

19. Mojekwu T.O., Yama O.E., Ojokuku S.A. and Oyebadejo S.A. (2011). Hypoglycaemic effects of aqueous extract of Aframomum melegueta leaf on Alloxan-induced diabetic male albino rats. Pacific Journal of Medical Sciences, 8:28-36.

Olaitan H.M., *Nwinyi F. C ., Akumka D.D. and Mohammed A. 